\title{
Esthetic Rehabilitation of Amelogenesis Imperfecta: A Case Report
}

\author{
K. Mayuri, M. P. Srujana, K. Anil Kumar \\ Department of Paediatric and Preventive Dentistry, Kamineni Institute of Dental Sciences, Nalgonda, Telangana, India
}

Email for correspondence: komu.mayuri@gmail.com

\begin{abstract}
Amelogenesis imperfecta (AI) is a genetic disease affecting primary and permanent tooth enamel. The affected teeth are disturbed in coloration, thickness, and resistance. The rehabilitation of AI in a child must take into account the development of the child's teeth, the health of the periodontal tissues, and the maxillary and mandibular growth. This article reports the esthetic and occlusal rehabilitation of a 14-year-old girl affected with hypocalcified AI.
\end{abstract}

Key words: Amelogenesis imperfecta, esthetic, occlusal rehabilitation

\section{INTRODUCTION}

Amelogenesisimperfecta(AI)isatermforaclinically andgeneticallyheterogeneousgroup ofconditionsthat affect the dental enamel, occasionally in combination with other dental, oral, and extraoral tissues. Typical feature of $\mathrm{AI}$ is the presence of enamel defects in both primary and permanent dentition. Morphological or biochemicalchangesmightbepresentelsewhereinthe body in association with AI. ${ }^{[1]}$

Witkop classified 14 different subtypes of AI exist with numerous patterns of inheritance and a variety of clinical manifestations. Based on the clinical and radiographic features, three broad types exist, i.e., hypoplastic, hypocalcified, and hypomaturation. ${ }^{[2]}$ Restoration of these defects is important not only because of esthetic and functional concerns but also there may be a positive psychological impact for the patient. ${ }^{[3]}$

AI may be inherited as an autosomal dominant, autosomal recessive, or an X-linked recessive disease. It arises from mutations that occur in one or more than one of four genes that are known to play a role

\section{Quick Response Code Article Info:}

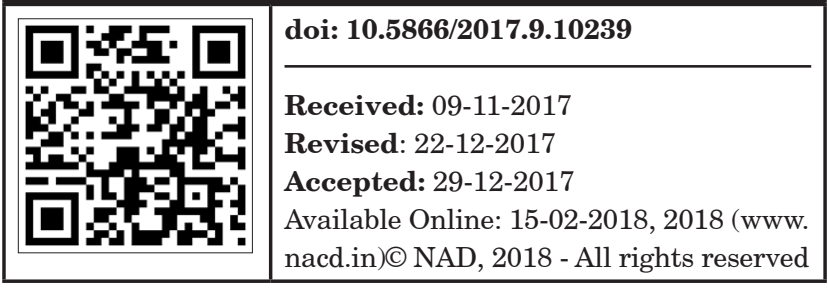

in enamel formation, namely, amelogenin (AMELX), enamelin, enamelysin (MMP20), and kallikrein (KLK4). ${ }^{[4]}$ The amelogenin gene on the X chromosome is implicated in genetic defects in X-linked AI, but the molecular basis is unclear in this and other forms of the disease. ${ }^{[5]}$ During amelogenesis, the enamel changes from a protein-rich soft tissue to a hard tissue entirely devoid of protein, and this change is dependent on certain molecular and cellular activities, which in turn, depends on the genes mentioned above. Any mutation in the genes will result in aberrations in the enamel. ${ }^{[6]}$

In the present case report, we tried to rehabilitate a child with AI whose oral condition had deteriorated due to poor oral hygiene.

\section{CASE REPORT}

A14-year-old girl was referred to the Department of Pediatric Dentistry, KIDS, Narketpally, with the chief complaint of generalized yellowish discoloration of teeth. On intra-oral examination, generalized yellowish discoloration of teeth [Figure 1], with prominent pitting on labial and buccal surfaces; attrition on upper and lower molars but with no sensitivity; dental caries in teeth no. 37 and 46, and missing 36 (extraction due to caries) was observed. The patient underwent extraction of 36, 5 years back. The patient's mother affirmed that the primary teeth also were affected with the similar yellowish discoloration. The surfaces of all teeth were rough, and irregular in shape generalized attrition was observed in molars of both the upper and lower 
arch [Figure $2 \mathrm{a}$ and $\mathrm{b}$ ]. The eruption pattern and sequence were found to be normal. On examination using probe, resistance was felt and tooth material was soft in consistency with mild flaking of residual enamel. Orthopantomogram [Figure 3] was advised to assess the generalized enamel hyperplasia. Based on history and clinical examination, a provisional diagnosis of AI, hypocalcified type, was made. The treatment was planned accordingly depending on the need. First, oral prophylaxis was done using ultrasonic scaler. Carious teeth in relation to 37 and 46 were restored using glass ionomer cement and were followed up periodically. Removable partial denture was not given in relation to 36 as there was mesial shift of 37 and an obvious space loss with respect to 36 . Stainless steel crowns were given to all the molars simultaneously by checking the occlusal height and maintaining proper vertical dimension of occlusion (VDO) [Figure $4 \mathrm{a}$ and b]. The patient was recalled after 2 weeks for assessing VDO and then planned for composite veneering of the upper and lower anterior teeth. The first proper shade of composite was selected using shade guide which is suitable to the patient's complexion. Hypoplastic enamel was removed up to $0.5 \mathrm{~mm}$, and masking agent was applied on the teeth. After the composite veneering of the upper and lower anterior teeth [Figure 5], the patient felt more confident about

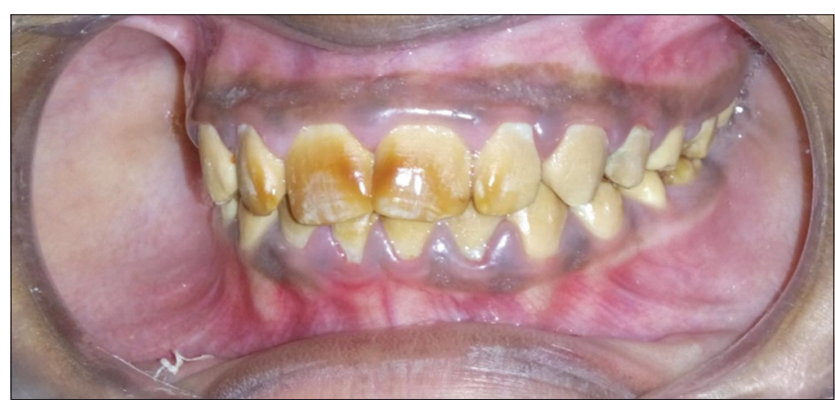

Figure 1: Preoperative clinical picture showing uniform yellowish discoloration of the teeth

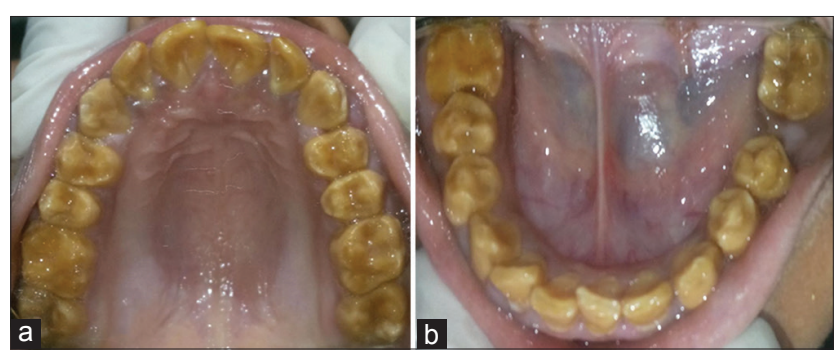

Figure 2: Uniform attrition on the occlusal surface of both the maxilla (a) and mandible (b) her smile. This interim management of AI using stainless steel crown in all the posterior teeth and composite veneering on both the upper and lower anterior teeth provided the patient with proper function, esthetics, and her interaction with the society showed a positive behavior.

\section{DISCUSSION}

Different approach is needed for the treatment of abnormal esthetic appearance, function, occlusion, phonation, and other negative gingival effects of AI. Esthetic abnormalities such as tooth sensitivity, discoloration, and abnormal texture cause psychological and functional difficulties for the patient. Treatment planning must focus on early diagnosis, pain management, prevention, stabilization, restoration of defects, and regular

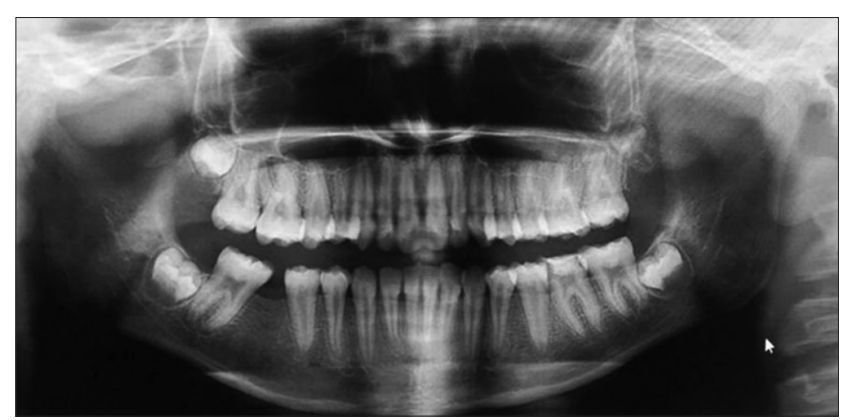

Figure 3: Orthopantomogram showing thin layer of enamel

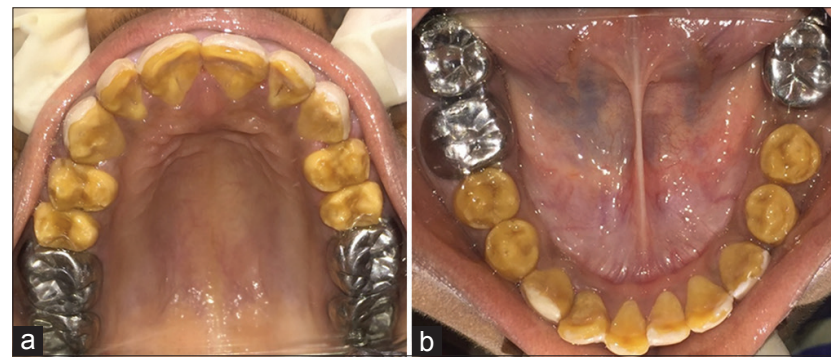

Figure 4: Placement of stainless steel crown in relation to (a) $16,17,26,27$; (b) $37,46,47$

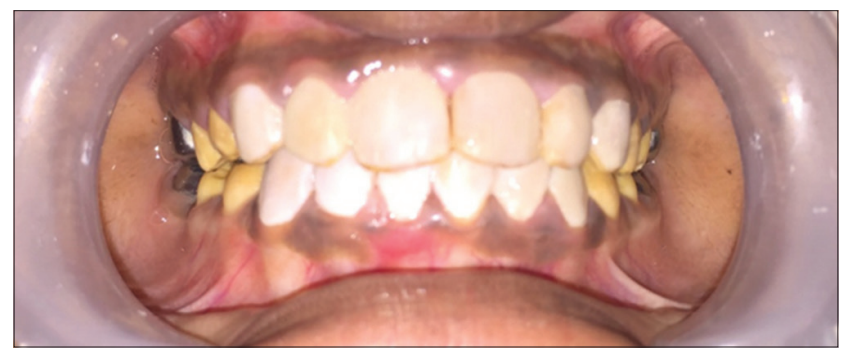

Figure 5: Composite veneering done on the upper and lower anterior teeth 
long-term management. ${ }^{[7]}$ The treatment plan should consider factors such as the patient's age, socioeconomic status, disease type and severity, and overall oral condition. ${ }^{[8]}$

In more or less equal manner, AI affects the enamel of all the teeth of the affected individuals, without reference to chronology, occasionally in association with other generalized conditions. ${ }^{[9]}$ A variety of clinical conditions can be presented with AI. The most common findings comprise extensive loss of tooth tissue, tooth sensitivity, excessive attrition leading to a short clinical crown, spacing in the anterior region of the dentition, normal or light proximal contacts in the posterior region, and a general enamel caries resistance. Abnormal tooth eruption, morbid root and coronal resorption, congenitally missing teeth, malocclusion, anterior open bites, pulpal calcification, dentin dysplasia, hypercementosis, root malformation, and taurodontism have been commonly seen. The most important feature of AI is surface irregularities and the crown discoloration mainly of yellowish-brown shade. ${ }^{[10]}$

\section{CONCLUSION}

AI is a serious problem resulting in reduced oral health quality of life. Psychology of the patient is affected negatively due to the esthetic concerns. It should be identified promptly and treated, and existing dentition should be protected so that teeth can be conserved as much as possible. Oral rehabilitation will certainly provide a good prognosis, and there are less clinical complications. The patient should be counseled and motivated to maintain good oral hygiene. Multidisciplinary approach is important for success of the treatment if accompanied by other dental anomalies.

\section{REFERENCES}

1. Backmon B. Inherited enamel defects. Ciba Found Symp 1997;205:175-82.

2. Douglas BN, Allen DD, Bouquot CM. Oral and Maxillofacial Pathology. $2^{\text {nd }}$ ed. Philadelphia, PA: Saunders; 2007. p. 89-106.

3. Ozturk N, Sari Z, Ozturk B. An interdisciplinary approach for restoring function and esthetics in a patient with amelogenesis imperfecta and malocclusion: A clinical report. J Prosthet Dent 2004;92:112-5.

4. American Academy of Pediatric Dentistry Clinical Practice Guidelines: Guideline on Dental Management of Heritable Dental Developmental Anomalies. Reference Manual; 20152016. p. 266-71.

5. Seow WK. Clinical diagnosis and management strategies of amelogenesis imperfecta variants. Pediatr Dent 1993;15:384-93.

6. Lakshman B, Revathy V, Suganthi, Geethalakshmi, Kumar SP. A unique case of amelogenesis imperfecta. Pediatr Dent Care 2016;1:109.

7. Gadhia K, McDonald S, Arkutu N, Malik K. Amelogenesis imperfecta: An introduction. Br Dent J 2012;212:377-9.

8. Greenfield R, Iacono V, Zove S. Periodontal and prosthodontic treatment of amelogenesis imperfecta: A clinical report. J Prosthodont Dent 1992;68:572-4.

9. McLarty EL, Giansanti JS, Hibbard ED. X-linked hypomaturation type of amelogenesis imperfecta exhibiting lionization in females. Oral Surg Oral Med Oral Pathol 1973;36:678-85.

10. Moretti AB, Sakai VT, Oliveira TM. Oral management of a child with mixed dentition affected by amelogenesis imperfecta. J Dent Children 2007;74:157-60. 